\title{
The International Space Station Evolution Data Book: An Overview and Status
}

\author{
Jeffrey Antol ${ }^{1}$, Catherine A. Jorgensen ${ }^{2}$ \\ ${ }^{I}$ NASA, Aerospace Systems Concepts and Analysis, NASA Langley Research Center, Mail Stop 328, \\ Hampton, VA 23681-2199, Phone: 757-864-5804, Fax: 757-864-1975, j.antol@larc.nasa.gov \\ ${ }^{2}$ Federal Data Corporation, Space Concepts Analysis Section, NASA Langley Research Center, Mail Stop 328, \\ Hampton, VA 23681-2199, Phone: 757-864-1455, Fax: 757-864-1975, c.jorgensen@larc.nasa.gov
}

\begin{abstract}
The evolution and enhancement of the International Space Station (ISS) is currently being planned in conjunction with the on-orbit construction of the "baseline" configuration. Three principal areas have been identified that will contribute to the evolution of ISS: Pre-Planned Program Improvement $\left(\mathrm{P}^{3} \mathrm{I}\right)$, Utilization \& Commercialization, and Human Exploration and Development of Space (HEDS) missions. The ISS Evolution Strategy, under development by the Spacecraft and Sensors Branch of NASA Langley Research Center, seeks to coordinate the $\mathrm{P}^{3} \mathrm{I}$ technology development with Commercialization/Utilization activities and HEDS advanced mission accommodation to provide synergistic technology developments for all three areas. The focal point of this proposed strategy is the ISS Evolution Data Book (EDB), a tool for aiding the evolution and enhancement of ISS beyond Assembly Complete. This paper will discuss the strategy and provide an overview of the EDB, describing the contents of each section. It will also discuss potential applications of the EDB and present an example Design Reference Mission (DRM). The latest status of the EDB and the plans for completing and enhancing the book will also be summarized.
\end{abstract}

\section{ISS EVOLUTION STRATEGY}

The current design and development of the International Space Station (ISS) has been achieved through the outstanding efforts of many talented engineers, designers, technicians, and support personnel who have dedicated their time and hard work to producing what will be the world's most capable Space Station. Despite these efforts, the current design of the ISS has limitations that have resulted from cost and technology issues. Regardless, the ISS must evolve during its operational lifetime to respond to changing user needs and long-term national and international goals. As technologies develop and user needs change, the ISS will be enhanced to meet these demands. The planning of these enhancements has begun in order to prevent a significant lapse in time between the baseline design and the realization of future opportunities.

The evolution and enhancement of the ISS is currently being examined in parallel with completion of the on-orbit "baseline" configuration. Three principal areas have been identified that will contribute to the evolution of the ISS: Pre-Planned Program Improvement $\left(\mathrm{P}^{3} \mathrm{I}\right)$, Utilization \& Commercialization, and Human Exploration and Development of Space (HEDS) missions. The $\mathrm{P}^{3} \mathrm{I}$ Working Group is assessing ISS technology needs and developing associated technology insertion roadmaps. The ISS Commercialization Working Group is formulating plans for accommodation of commercial applications, while NASA science organizations are examining ways to expand experiment utilization capabilities. Additionally, HEDS mission initiatives are proposing ISS based technology test-beds, through which enhancements of ISS systems and operations may also be realized. An ISS Evolution Strategy is proposed that coordinates the $\mathrm{P}^{3} \mathrm{I}$ technology development with Commercialization/ Utilization activities and HEDS advanced mission accommodation to provide synergistic technology developments for all three areas (see Figure 1). 


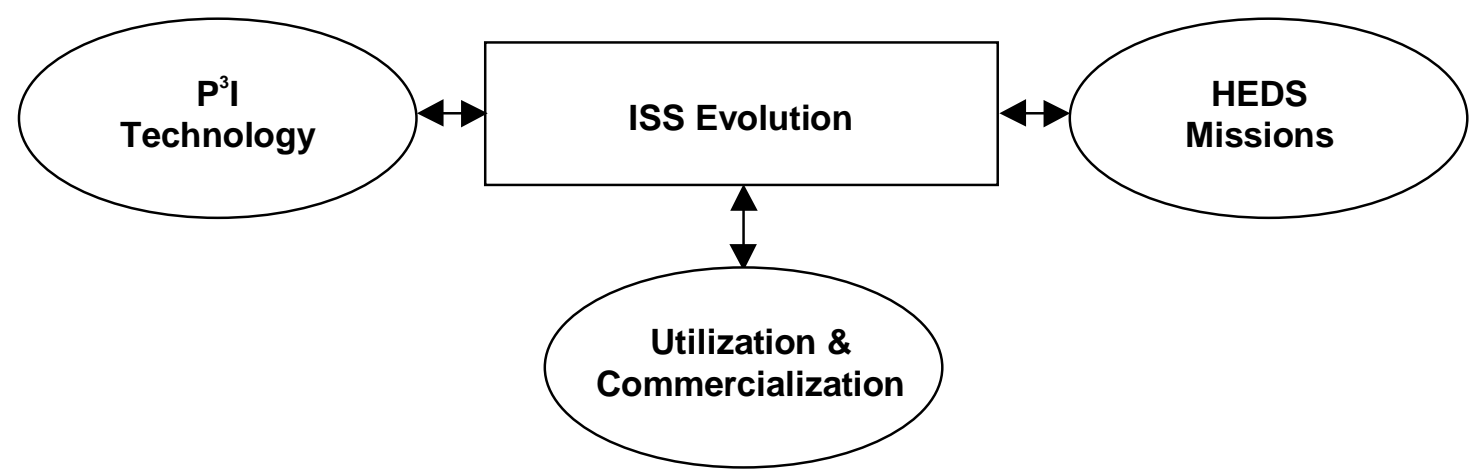

FIGURE 1. ISS Evolution Strategy.

The ISS Evolution Strategy seeks to partially fill the void left by the elimination of space station evolution activities during the redesign effort that created the current ISS configuration. The focal point of this proposed strategy is the ISS Evolution Data Book (EDB), under development by the Spacecraft and Sensors Branch of NASA Langley Research Center. The Data Book is being created as a tool for aiding the evolution of ISS beyond Assembly Complete, through enhancement and commercialization activities.

\section{EVOLUTION DATA BOOK OVERVIEW}

The EDB has three primary purposes. First, it provides an overview of the ISS baseline design at a subsystem level, with potential growth areas identified. Second, it presents the current and future options for the application of advanced technologies and the associated potential impacts. Finally, it consolidates this information in one location for the engineering, research and commercialization communities to help generate ideas and options for synergistic ISS enhancement.

The EDB is divided into two principal volumes: "Baseline ISS" and "Evolution" (see Table 1). Volume I Baseline ISS, presents the current design configuration of ISS. It begins with a brief overview of each of the 22 major components of the ISS, including individual laboratories owned by the ISS International Partners, the integrated truss segments, the various nodes, propulsion modules, and science facility modules. These brief descriptions provide the reader with an overall understanding of the major components of the station.

Volume I also provides a subsystem level overview of the ISS baseline design. A high-level technical description is provided for each of the nine individual critical sub-systems onboard the ISS. These include Power; Thermal; Communications; Command and Data Handling; Guidance, Navigation and Control; Propulsion; Environmental Control and Life Support Systems; Robotics; and Structures and Mechanisms. The capabilities of each subsystem, the potential limitations of each subsystem, and a description of potential growth opportunities and growth limitations are presented.

Additionally, current plans for operation and utilization of the ISS are presented, including utilization of crew time, traffic models, space availability, and resource availability including bandwidth and data rates for communications, power, thermal, and system ground commanding availability. Descriptions of each of the internal facilities on board the ISS are included. These facilities will provide specific services to payloads that are either currently planned, research-based activities or future commercial-type endeavors. Examples of the facilities included are the Combustion Facility and Fluid Physics Facility that are used in materials research, the Life and Microgravity Science Gloveboxes which are fully contained facilities for performing biological or materials activities, and the EXPRESS Racks to name a few. Along the same lines, it provides location and resource information on the external payload facilities including the U.S. and Japanese facilities. The European Space Agency facility and Russian facility will be described as information becomes available. 
TABLE 1. ISS Evolution Data Book Contents, Baseline Release

\begin{tabular}{|c|c|}
\hline BASELINE ISS & EVOLUTION \\
\hline $\begin{array}{l}\text { Part 1: Baseline Assembly Complete } \\
\text { Description } \\
\text { - Sub-system Descriptions, which include } \\
\text { scars, if any, for growth: } \\
\text { - Power } \\
\text { - Thermal } \\
\text { - Communications } \\
\text { - GN\&C } \\
\text { - Data System } \\
\text { - Crew Systems } \\
\text { - Propulsion } \\
\text { - Structures \& Mechanisms } \\
\text { - Robotics } \\
\text { Part 2: Baseline Utilization \& Ops Plans } \\
\text { - Experiment Facility Descriptions } \\
\text { - } \quad \text { Resource Timelines \& Margin Summary } \\
\text { - } \text { ISS Cargo Traffic }\end{array}$ & $\begin{array}{l}\text { Part 3: Advanced Technologies \& Utilization } \\
\text { Opportunities } \\
\text { - } \quad \text { Pre-Planned Program Improvement }\left(\mathrm{P}^{3} \mathrm{I}\right) \\
\text { Technologies } \\
\text { - } \quad \text { Proposed Research and Commercialization } \\
\text { Activities } \\
\text { Part 4: Design Reference Missions for ISS } \\
\text { Evolution } \\
\text { - Implementation of }\left(\mathrm{P}^{3} \mathrm{I}\right) \text { Technology Sets } \\
\text { - } \quad \text { Fnergy Storage Enhancement } \\
\text { - } \quad \text { Advanced Communications Tower } \\
\text { - } \quad \text { TRANSHAB } \\
\text { - } \quad \text { Tether for ISS Orbit Maintenance } \\
\text { - } \quad \text { Advanced Space Transportation Systems }\end{array}$ \\
\hline
\end{tabular}

Volume II - Evolution, describes advanced technologies and utilization opportunities. The advanced technologies being investigated by the Pre-Planned Program Improvement $\left(\mathrm{P}^{3} \mathrm{I}\right)$ Working Group led by the NASA Johnson Space Center in Houston, Texas are discussed. The proposed ISS technology enhancements that are known at this time and associated roadmaps for the investigation of each area are also provided.

Volume II also summarizes several Design Reference Missions (DRM) that are being investigated for postassembly complete utilization and enhancements. The DRMs are concepts for potential ISS evolution and include a summary of analyses and assessments to examine the viability of the concepts. These include launch-on-demand logistics, enhanced communications capabilities utilizing the Advanced Communications Tower and utilizing a new module, TransHab, for increased pressurized volume onboard the ISS.

Finally, Volume II presents ISS commercialization information and opportunities for possible commercial ventures, advanced scientific research opportunities and an overview of the synergistic applications of the ISS for the HEDS missions.

\section{POTENTIAL APPLICATIONS}

The EDB has several potential applications, including: a source of overview information for NASA and ISS personnel to aid strategic planning; an information resource for private industry to aid commercialization efforts; and a guide for the science research community to aid advancement of ISS experiment utilization.

\section{Information Source}

The ISS Evolution Data Book is intended to provide high level technical information to the science research community, commercial industry, academia, and the general public. Used as a desktop reference, the data book not only provides high-level finger-tip information on the technical aspects of the ISS, but also provides further references for more detailed information. 
The data book should be used as a planning tool and a desk reference and not as a design tool for the development of a system, product, or any other entity. It is intended for use as a reference source to provide a high-level technical overview of the ISS, its capabilities, future options for enhancements, and opportunities for commercial use. It is anticipated that the data book can act as a catalyst to facilitate innovative uses of the ISS and to facilitate the application of non-aerospace technologies to enhance the many capabilities of the ISS.

\section{Commercialization}

The data book can also be used as part of the marketing strategy for developing the ISS as an international marketplace. NASA Langley Research Center, in conjunction with NASA Headquarters, plans to distribute this information through the Commercial Space Centers (CSCs), through face-to-face contact at commercial and industrial trade shows, through the NASA commercialization initiatives at headquarters, Johnson Space Center, and Langley Research Center, and via a publicly available web site. This web site is planned to have links not only to NASA public web sites, but also to business associations. As information becomes available, the document will be revised to remain current for industry. The updated information will be available electronically and via hard copy if desired. A database of interested firms will be established to ensure that the flow of information remains constant.

\section{Utilization}

The high-level information on the technical aspects of the ISS, and the references defined for detailed information, will be of interest to payload developers in planning for enhanced experiment facilities and associated experiment hardware. The EDB overview of the ISS subsystems and the planned experiment facilities will provide payload developers with an understanding of ISS science research capabilities. However, the EDB will not serve as a "user's guide" for payload accommodations. Additional documentation will be available from the ISS program office for this purpose.

\section{DESIGN REFERENCE MISSIONS}

As discussed previously, the Design Reference Missions (DRMs) are concepts for potential ISS enhancements and evolution. DRMs are defined and analyzed to examine the viability of concepts and to identify synergistic technology investments that can augment performance of the ISS. Each DRM includes a description of the proposed enhancement, identification of ISS interface requirements, description of the enhanced ISS configuration, and the assessment/analysis of the impacts to the ISS caused by the enhancement.

\section{DRMs and Associated Analyses}

Several DRMs (see Table 1) are currently under development, including the Advanced Communications Tower DRM, examining an enhanced communication capability for ISS, and the TransHab DRM, the application of a new pressurized module for increased volume onboard the ISS. Two additional DRMs are planned for the next revision of the EDB: the ISS Accommodation of Exploration Technology Development and Launch Express Logistics. The set of DRMs will continually evolve as additional DRMs are developed and others are discontinued. Each DRM will require specific analyses and simulations that are particular to each concept such as the following:

- Kinematic Simulation

- ISS Control Analysis

- ISS Microgravity Analysis

- Communication Coverage and Interference Analyses

- ISS Immersive Accommodation Environment Simulation

- Technology Assessments

- $\quad$ System Impacts 


\section{Example DRM - Launch Express}

The "Launch Express" DRM, a concept for enhancing ISS logistics capabilities, is currently in development and serves as a good example of a typical DRM (The Launch Express DRM is not included in the baseline release of the EDB, however, it will be provided in the first revision of the document). The Launch Express DRM examines "Launch-on-Demand" delivery of supplies to ISS. The concept is to deliver logistics and resupply items on short notice to ISS for unplanned scenarios and emergency situations. This capability would allow short term, quick turn-around missions (2-10 days) that would complement the planned Shuttle and automated ISS resupply missions. There are several potential applications for this capability:

Delivery of Critical Orbital Replacement Units (ORUs) - Once an on-orbit critical spare is used, the ISS crew must wait for the next resupply flight to replenish the on-orbit backup. The new spare could be delivered within several days, perhaps preventing costly changes to the logistics manifest

Support of Existing Resupply Vehicles - In the event of a delay, or the catastrophic loss of a resupply vehicle, equipment and supplies could be delivered to sustain ISS capabilities in the interim.

Delivery of Medical Supplies - Medical supplies could be delivered quickly in the event of a unique medical situation, perhaps preventing the use of the Crew Return Vehicle (CRV) and loss of ISS operations

Delivery of Payloads and Payload Resupply - The Launch Express capability could be used to deliver small payloads and associated instruments in the event of a near-term science opportunity

A proposed implementation of the concept includes use of an air-launched vehicle. The use of an air-launched vehicle would allow launches to be accurately phased in order to quickly reach ISS orbit. Preliminary analysis indicates there are air-launched vehicles that can deliver approximately $350-400 \mathrm{~kg}$ to ISS orbit (407 km @ 51.6 $)$, with an estimated $100 \mathrm{~kg}$ of that mass being usable payload.

Once on-orbit, the Launch Express vehicle would rendezvous with the ISS and conduct proximity operations with the Space Station Remote Manipulator System (SSRMS) or Japanese Experiment Module (JEM) RMS. The vehicle would then be grappled by the SSRMS or JEM RMS and await either an Extra Vehicular Activity (EVA) for retrieval of external ORUs or insertion of the payload portion of the vehicle into the U.S. or JEM airlock. A preliminary examination of the Launch Express/ISS interface requirements is included in the DRM.

In order to examine the impact that the Launch Express concept would have on ISS logistics, an analysis was conducted to determine if an air-launched capability existed that could deliver ISS ORUs that were designated as "critical". A total of 94 critical spares, with mass and volume defined, were contained in the ISS "Horseblanket" spreadsheet. Of those 94 spares, 73 were less than the $100 \mathrm{~kg}$ estimated payload capability of the air-launched vehicle and had a volume within the JEM airlock capability $(0.97 \mathrm{~m} \times 0.62 \mathrm{~m} \times 0.8 \mathrm{~m})$. Thus, the Launch Express concept could accommodate approximately $78 \%$ of the ISS critical spares.

Additional simulation and analyses that may be conducted on the Launch Express DRM include an ISS Immersive Accommodation Environment simulation and kinematic simulation to validate capture and installation by the SSRMS and/or the Japanese RMS. ISS resource impact studies and ISS environment vulnerability analyses will also be needed to assess additional impacts to the ISS.

\section{STATUS}

The baseline version of the ISS Evolution Data Book is planned to be released in November 1999. Current activities are focused on the first revision of this document, which includes updating any baseline information and expanding the evolution portion of the document, Volume II. As the ISS approaches the Assembly Complete stage, it is anticipated that operational information will become available which could impact future ISS capabilities as well as utilization. These document revisions will include this information. Revision A is planned for release in March 2000. The web site (http://centauri.larc.nasa.gov/issdatabook) contains a general overview of 
the book and its purpose with a link to the two volumes, as well as other relative links. The web site and the document are available to the general public.

\section{CONCLUDING REMARKS}

The ISS Evolution Data Book (EDB) is currently under development by the Spacecraft and Sensors Branch of NASA Langley Research Center. The EDB will serve as a tool for aiding the evolution and enhancement of ISS beyond Assembly Complete. The book seeks to coordinate $\mathrm{P}^{3} \mathrm{I}$ technology development with Commercialization/Utilization activities and HEDS advanced mission accommodation to focus synergistic technology developments for all three areas. The baseline version of the ISS Evolution Data Book is planned to be released in November 1999. Revision A is planned for release in March 2000.

\section{ACKNOWLEDGMENTS}

The authors would like to acknowledge Mr. Lewis L. Peach, former Director of Advanced Projects at NASA Headquarters, for his support in the Evolution Data Book effort.

\section{REFERENCES}

Jorgensen, C., Antol, J., F. Stillwagen, C. Roithmayr, P. Cosgrove, G. Hajos, J. Hall, Jr., G. Ganoe, "International Space Station Evolution Data Book", NASA/SP-1999-6109, NASA Langley Research Center, November 1999.

Jorgensen, C. "An Initial Strategy for Commercial Industry Awareness of the International Space Station" in Proceedings of the Annual Symposium, International Space Station: The Next Marketplace, International Space University, Strasbourg, France, 1999. 